\title{
Challenges of remote assessment in higher education in the context of COVID-19: a case study of Middle East College
}

\author{
Fiseha M. Guangul ${ }^{1}$ (D) Adeel H. Suhail ${ }^{1} \cdot$ Muhammad I. Khalit $^{1}$ • \\ Basim A. Khidhir ${ }^{1}$
}

Received: 31 July 2020 / Accepted: 15 October 2020 / Published online: 21 October 2020

(C) Springer Nature B.V. 2020

\begin{abstract}
Due to the unprecedented COVID-19 incident, higher education institutions have faced different challenges in their teaching-learning activities. Particularly conducting assessments remotely during COVID-19 has posed extraordinary challenges for higher education institutions owing to lack of preparation superimposed with the inherent problems of remote assessment. In the current study, the challenges of remote assessment during COVID-19 incident in higher education institutions were investigated taking Middle East College as a case study. For the study, questionnaires were prepared and data from 50 faculties were collected and analyzed. The study focused on the challenges of remote assessment in general and academic dishonesty in particular. The main challenges identified in remote assessment were academic dishonesty, infrastructure, coverage of learning outcomes, and commitment of students to submit assessments. To minimize academic dishonesty, preparing different questions to each student was found to be the best approach. Online presentation was also found to be good option to control academic integrity violations. Combining various assessment methods, for instance report submission with online presentation, helps to minimize academic dishonesty since the examiner would have a chance to confirm whether the submitted work is the work of the student.
\end{abstract}

Keywords Summative assessment and testing · COVID-19 $\cdot$ Remote assessment · Academic dishonesty $\cdot$ Proctored exam

\section{Introduction}

Due to COVID-19 pandemic disease, almost all sectorial activities around the world has been affected. Higher education institutions are one of the sectors in which most

Fiseha M. Guangul

fiseham2002@yahoo.com

Extended author information available on the last page of the article 
activities are affected since conducting face-to-face class and laboratory activities would require physical interactions. Once it is recognized that the virus is transmitted by direct contact and surfaces in the immediate environment with infected person or with objects used by the infected person (WHO, 2020), higher institutions are forced to suspend face-to-face classes. Consequently, most higher institutions have rushed to remote teaching and online classes. This does however create unprecedented challenges in terms of getting used the technologies and in accessing essential facilities such as laboratories (Cooper \& Tschobotko, 2020).

Since there were no clear policy and guidelines in most higher institutions on online teaching, several questions such as what to teach, how to teach, what should be the duties of the teacher and the student, the workload of the teacher, the teaching environment, and the implications for education equity, etc., were not clear. Problems such as the infrastructure, teachers' and students' experience on online teaching, the change on working time due to COVID-19 for some part-time students, and the inconvenience of working at home are additional challenges of remote teaching (Zhang et al., 2020). The existing and inherent remote teaching problems superimposed with the current and unprecedented problems, i.e., unavailability of policies, guidelines, enough infrastructure and experiences of teachers and students make the challenge more difficult. Kebritchi et al. have studied the issues and challenges faced in online teaching and identified three major categories of challenges that are related with instructors, learners, and content development. Figure 1 shows the specific issues and challenges of online education environment (Kebritchi et al., 2017).

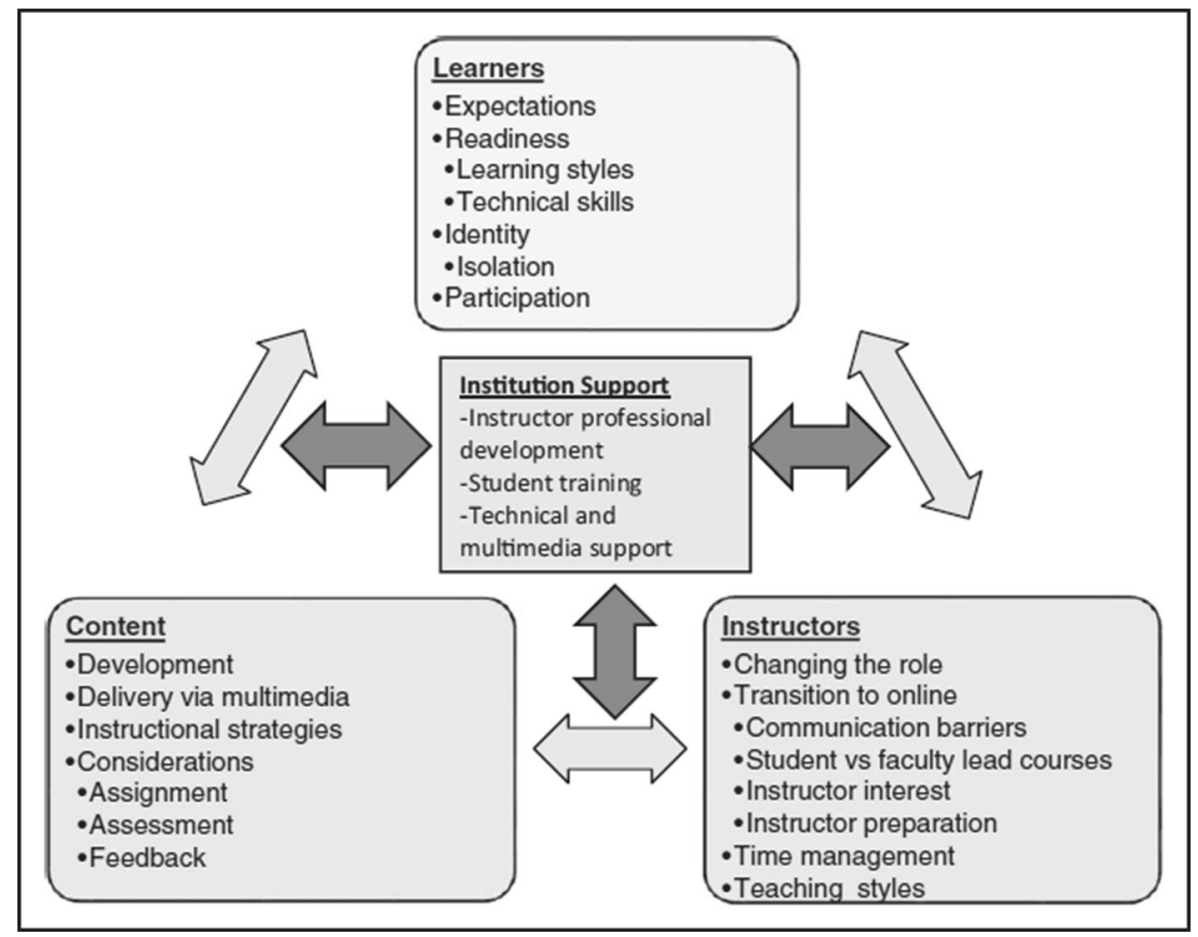

Fig. 1 Three major components and the related issues in an online education environment (Kebritchi et al., 2017) 
The other challenge related to COVID-19 is assessing students remotely. In higher institution, assessment has three major purposes: (1) to support learning, (2) to execute accountability, and (3) to provide certification, progress, and transfer (Archer, 2017; Capsim, 2020). Formative and summative assessments in conjunction with appropriate feedback systems are used to support learning in higher education. This means employing assessment data in a diagnostic approach to determine competence, gaps, and progress so learners may adapt their learning strategies and teachers their teaching strategies. Assessment for accountability is a function of responsibility. This is mainly achieved through providing evidence that learning is being promoted. As a means of accountability, international and national comparative and benchmark would also be established to get credibility. Assessment can also serve the purpose of offering certificate for learning of the intended outcomes, guaranteeing progress and transfer (Archer, 2017).

In higher institution programs, modules have specific learning outcomes. These outcomes provide information on learning levels that students need to achieve targeted educational objectives (Al-Shammari, 2011). Hence, the objectives of assessment are directly linked with the achievement of the learning outcomes both by supporting the learning process and measuring the degree of learning.

In recent years, enrolment for online courses has grown in faster rate than overall enrollments in higher education. Nearly $30 \%$ of US college and university students are taking at least one online course, and the trend is expected to increase in the future. As part of the online courses, an area of focus that deserves special attention is the assessment of student learning. This includes how instructors design and implement formative and summative assessments to measure the student progress and learning, providing effective feedback, and insuring academic integrity (Kearns, 2012). Online assessments have their own sustained and inherent advantages and challenges. However, higher education institutions have faced another additional challenge during the current unprecedented COVID-19 incident due to lack of preparation of institutions, teachers, and students. In the current study, the available options of remote assessment in higher education institutions are reviewed. The study also investigated the challenges faced by higher academic institutions in COVID-19 lockdown period considering a case study of Middle East College. Particularly, to address the academic dishonesty in remote assessment an investigation is carried out to identify and prioritize the appropriate assessment type for various modules.

\section{Types of remote assessment}

In recent years, online learning is adopted in many higher institutions and assessing students remotely is being challenging, particularly in ensuring academic integrity. Educators are compelled to devise a strategy for an appropriate remote assessment method. A variety of remote assessments are available to evaluate students' online learning. These assessments are broadly classified as (1) remotely proctored exams (time-constrained) and (2) open-ended assessments. 


\subsection{Proctored exams}

This exam is a time bounded and proctored, and commonly used in the classrooms. Proctored exams can also be done remotely by using various learning management systems such as Canvas and Sakai. In addition, Proctortrack software can also be used for remote assessment by using webcams to track student activity during exam time to assist the instructor whenever suspicious actions are taken by the students (Rutgers, 2020).

However, proctored remote exams have several drawbacks and the major ones are mentioned below.

1. Remote proctored exams are often more stressful for students than in-person proctored exams which would affect the student performance adversely.

2. Remote proctored exam requires well-established infrastructure setup, software, and hardware, both on the instructor and student side. In addition, the application software such as ProctorTrack could create "false positive" flags that mislead the instructor.

3. In remote proctored exam failure of software, hardware, or internet connection could be experienced. Hence, contingency plan should be designed before the exam is started.

4. Due to personal or cultural reasons students may not be willing to stay under the camera supervision.

5. If a student faces technical difficulties on the system during exam time, supporting the student and fixing the problem remotely will not be easy (Rutgers, 2020).

\subsection{Alternatives to proctored remote exams}

Your learning goals are an excellent place to start when alternative assessments are considered. The expectations from students when they complete the course, and the way they have to demonstrate their learnings are the key factors to identify the assessment types.

As the objectives of assessment is to evaluate the performance of students against the learning outcomes and promoting learning activities, certain assessment methods would be appropriate and less problematic to achieve the intended objectives in remote assessing. Hence, the following assessments can be applied based on the nature of the course and questions.

Series of quizzes Quizzes offer a low-stakes opportunity for students to demonstrate their understanding on the materials provided. It also gives ongoing information about students' understanding and serves as a feedback for improvement. Quizzes are also easier to randomize questions by using various application software such as Canvas and Sakai to make cheating more difficult.

Open-book, take-home assessments These assessments are conventional and used under the traditional teaching-learning process also. However, when there is no possibility of proctored exam, take-home exam can serve as the main assessment method to 
cover the learning outcomes. To make sure that the assessment is done by the student, online oral presentation, and question can be included. The challenge of take-homeexam is preparing more conceptual questions that cannot be found directly and easily in any type of sources, such as the internet and textbooks.

Professional presentations or demonstrations These assessments can be done in audiovisual and are good demonstration of the students' understanding especially when presentation is conducted online. The presentation can be done using any web based online conferencing system, such as ZOOM, MS Team, and BigBlueButton.

Annotated bibliography Annotated bibliography is a summarization of essential ideas contained in a document, thesis, research article, etc. and discusses how they relate to your own ideas or thesis. An evaluative annotation adds your judgments about the quality of the author's ideas. Annotated bibliography project gives students a choice in selecting works while assessing their higher-order abilities to evaluate sources, compare multiple perspectives, and provide rationales for their choices ("Organizing your social sciences research paper, 2020; Rutgers, 2020).

Fact sheet A fact sheet provides information to readers in a clear and concise format. A fact sheet can be presented on a piece of paper or digitally, and it informs people about a business, organization, product, service, campaign, event, or another topic. Generally, a fact sheet should center around one issue and should not be more than one page with a clear, easy-to-read layout. Hence, students can create a fact sheet in a single page on various topics, works, or companies. Students may select their topic, or it can be assigned by the instructor.

E-portfolio E-portfolio is considered a learning and assessment tool. Students compile their best or representative work from the semester, writing a critical introduction to the portfolio and a brief introduction to each piece. Students' achievement can be evaluated collectively for a module improvement. It can also be useful to organize, sample, and assess what students gained out of it. E-portfolios enable faculty not only to observe what students know and can do, but also to indicate how students learn through their reflections (Rutgers, 2020).

\subsection{Precautions in the preparation of open-book assessments in quantitative courses}

Open-book and take-home assessments are vulnerable to academic dishonesty. Academic dishonesty is not only ultimately disadvantaging the cheater, but other students may feel their hard work is not rewarded. Even a perception of cheating, which is more likely to occur in take-home exams would harm student morale. Consequently, some studies show that frequent in-class assessments are more effective for learning retention than take-home exams (Haynie III, 2003). In take-home assessment, students have access to the internet and can browse the sentences of the assessment or keywords and find solutions if the assessment is copied from books or other sources. Hence, special care is required when open- 
book assessment is prepared. Precautions that should be taken during assessment preparation are as follows:

- Ask more conceptual questions in which students cannot browse and found from various sources. For instance, ask questions like explain why the current system efficiency is lower than the efficiency in the industries and explain the problem in the current approach and suggest the proper approach to address the given problem.

- Eliminate multiple-choice and fill-in questions. Rather ask students to show the procedure, steps, and principles and to justify why they select the method they have used for their work.

- If using problems from a textbook, change not only the numbers but also the names (e.g., John to Alice) and the scenario (e.g., pulling a boat into letting a kite string out). Use letters and variables in place of specific numbers. The reason for this is that popular textbooks will probably have many of their problems already solved online somewhere else.

- When randomizing the exam, do not just randomize numbers. Also randomize discrete parts of the problem. For instance, one version might have a problem like "maximize the volume of the box given its surface area" whereas another version might have "minimize the surface area of a box given its volume". The numbers can even be the same for the two versions.

- Avoid questions that consist of only simple computations. For example, instead of "calculate the output power", present students with some application in which they also have to explain how to improve the output power. "Explain how the output power changes if ..." "or Discuss the effect of surrounding temperature on the efficiency of ..." are good alternatives.

- Be clear about the rules for the take-home exam (including collaboration policies and what sources may be used) and explain why you have set the rules you have.

- Remind students about the college academic integrity policies. Also remind students that being faithful and maintaining integrity are the key values for long-lasting success.

- Whenever necessary, ask students to sign the college academic integrity intent prior to the take-home-exam. There are some evidences that suggest signing a pledge before taking an exam is an effective deterrent (McCabe et al., 2012).

- Set time limits for the take-home exam to deter contract cheating and help-seeking.

- When there are possibilities track students when they take the exam to make unauthorized collaboration easier to detect.

- Since the risk of cheating is increased when students feel "stuck," offer students an opportunity to ask clarification when it is required. For instance, giving a chance to ask questions within the exam time or provide hints when students are confused on what they are asked (McCabe et al., 2012; Rutgers, 2020).

\subsection{Quality criteria of assessment}

In choosing the type of assessments there should be certain quality criteria that ensure the assessment objectives are met. In this regard, the following criteria would be considered in the choice of the assessment. 


\subsubsection{Validity}

As assessment main objective is to evaluate the students' learning on the specific learning outcome, the assessment method should be appropriate to evaluate the achievement of the learning objectives (Hsiao \& Watering, 2020).

\subsubsection{Reliability}

The most difficult issue in remote assessment is ensuring academic integrity. The assessment design should consider preventive measures to make assessment free from cheating and fraud. The preventive mechanisms during the assessment time and detecting mechanisms after submission should be employed (Hsiao \& Watering, 2020).

\subsubsection{Clarity}

During the assessment time, since there is no face-to-face communication and students may not have a chance to ask clarification, the assessment should be clear to students. Particularly when students are not familiar with the new assessment method, it is essential to explain the procedures and expectations clearly and provide related examples. This also applies if questions are asked at a different level than would normally be expected. Make sample questions, and if possible discuss these questions online with the students before issuing the assessment (Hsiao \& Watering, 2020).

\subsubsection{Avoid susceptibility for technical problem}

Commonly, in remote assessments, the instructor will not be in a position to solve the student's problem. The problem could arise as a result of hardware or software malfunctions, or due to lack of knowhow on the supporting materials by the student. It is important to consider how to deal with these kinds of problems in advance (Hsiao \& Watering, 2020)?

\section{Methodology}

\subsection{Remote assessment during COVID-19 lockdown at Middle East college}

Middle East College (MEC) is an accredited college by the Oman Academic Accreditation Authority (OAAA) and found in the Sultanate of Oman, Muscat. The college has over 4500 students in undergraduate and postgraduate studies of engineering, science and technology, business and management, and archives and record management programs which are affiliated with Coventry University, UK, and Breda University of Applied Sciences, the Netherlands.

Because of the unprecedented COVID-19 condition, MEC has suspended face-toface class on the third week of the spring 2020 semester. After COVID-19 incident has happed and before the class suspension was decided, the college was planning to implement an alternative option to continue the teaching-learning process online predicting the suspension of face-to-face classes by the government. The college has 
offered various trainings to the staff on an open-source web conferencing software. The first preference and focus of the training was on BigBlueButton web conferencing system. Hence, in the first day after the suspension of face-to-face class some faculties have used BigBlueButton and conducted the online class successfully. However, on the second day when many faculties were migrating to online teaching and try to use BigBlueButton connection problem has encountered by the faculties. Consequently, the college has decided to shift to MS Team and the necessary preparation has been carried out in linking the platform with the college system and providing training to the staff.

\subsection{MEC assessment strategy}

On 14 March 2020 the Supreme Committee on COVID-19 in Oman has announced that schools and other educational institutions will be suspend for a month starting from Sunday, March 15, 2020. The Committee has called on families to keep their children at home during this period. The Ministry of Education announced the suspension includes teaching and administrative staff, except for those employees whose presence is needed in the best interest of the work (Nair, 2020). Subsequently, after the suspension of the face-to-face class the college's focus was on the continuation of the class using an open-source web conferencing system, MS Team. The College has started the online classes without taking any decision on the assessments since there was an expectation of resuming class after 1 month. However, the Supreme Committee on COVID-19 has announced the extension of the lockdown in April until further notice is given (Observer, 2020).

As a result, the College has started examining the possible assessment methods that can be followed in the semester, and two guidelines were prepared. The first guideline document is "Supportive Measures and Assessment Approach" which describes the general principles and measures that are taken by the College to revise the semester assessment.

The supportive measure and assessment approach draws on the guidelines of the Ministry of Higher Education, Sultanate of Oman; the college's teaching and learning strategy; approaches undertaken by universities across the world in response to COVID-19; QAA's guidance documents; advice from the professional body partners including ICE and CILIP, UK; and consultations with staff and students. The alternate assessment approach is based on the following fundamental principles.

1. Health and well-being of the entire MEC community is the primary concern.

2. Provide opportunities to ensure that students' progression, graduation, and employability are considered.

3. Current distressing scenario should not negatively affect the graduation classification.

4. Securing overall academic standards and ensuring module-level learning outcomes are not affected.

5. Modes of assessment have to consider achievability of learning outcomes by students working from home, and also on how staff members can evaluate the work from home and record those decisions.

6. Modes of assessments should allow online student submission. 
7. The current period of study affects only a part of the overall program and its outcomes (MEC, 2020b).

Informed by the above principles, changes on the assessments were being taken and a detailed guideline was prepared. The prepared guideline that describes the changes in the assessment is the "Alternative/Revised Assessment Preparation Guide for Spring and Summer 2020". This guide draws on the Supportive Measures and Assessment Approach document, the inputs obtained from academic heads, professional service department heads, module leaders, and faculties. The document mandated that there shall only be a maximum of two assessments per module and that assessments shall be of an online format. A very detailed review of online assessment formats was undertaken by the Academic Affairs Committee and subsequently approved by the College Board to be used for the online assignment (MEC, 2020a).

\subsection{Questionnaires and analysis}

To investigate the remote assessment challenges faced by the faculties of different programs, a questionnaire was prepared and distributed to all faculties through Google Forms and 50 responses were collected. The questionnaires had three sections: section 1 , general information; section 2, assessment method (assignment, project); and section 3 , challenges of remote assessment.

\section{Result and discussion}

\subsection{General information}

In Middle East College, there are two types of modules. (1) modules with $100 \%$ course work and (2) Modules that have course work and end semester exam. As the nature of the assessment depends on the module type, in the questionnaire, two main types of assessments were indicated for the respondents to choose. From the responses of the questionnaire, it was also known that the number of students in one module varies between 5 and 125. As shown in Fig. 2, from the collected questionnaires, 64\% of the modules are $100 \%$ coursework modules and assessed in various coursework assessments, and the remaining $36 \%$ are assessed using both coursework assessments and end semester exam.

\subsection{Assessment method}

Respondents were asked to choose what type of assessment is appropriate for their respective module when the assessment strategy is changed from the normal assessment method which was used previously in the normal time to the current remote assessment method. The options given were two types. The first one is question-based assessment which is expected to be completed in a short span of time (maximum $3 \mathrm{~h}$ ). The second type is an assignment-based or project-based assessment which can be completed and submitted in a long span of time (from 1 to 4 weeks). As shown in Fig. 3, 68\% of the respondents have preferred assignment/project-based assessment 


\section{Nature of Module}

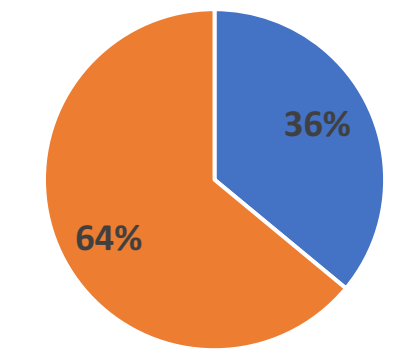

- 100\% Coursework

- Coursework \& End Semester Exam

Fig. 2 Module type

type for their specific module, and the remaining 32\% have preferred question-based assessment. As the degree of challenge for question-based assessment would be less compared to assignment/project-based assessment, the assessment is expected to be completed in a short time, and if the infrastructure is available proctoring could also be considered during the assessment time.

Hence, in the questionnaire, one question was provided for the respondents to know their preference whether proctoring students remotely is required. As shown in Fig. 4, $62.5 \%$ of the respondents have preferred not to proctor students when they are writing the assessment and the remaining $37.5 \%$ have preferred proctoring the students. Here, the reason why high percentage of respondents preferred not to proctor students when they are writing the assessment could be due to their concern on the inadequacy of the infrastructure to do the same.

For assignment/project-based assessment, various types of assignments or projects could be prepared and given to students. Assignment and project-based assessment

Assessment Style

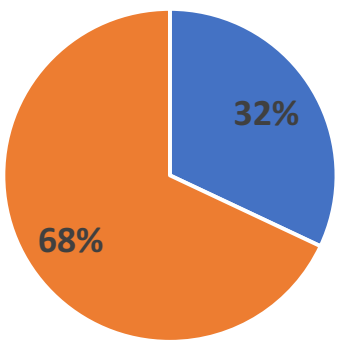

- Question-Based

- Assignment/ Project-Based

Fig. 3 Assessment style 


\section{Question-Based Assessment}

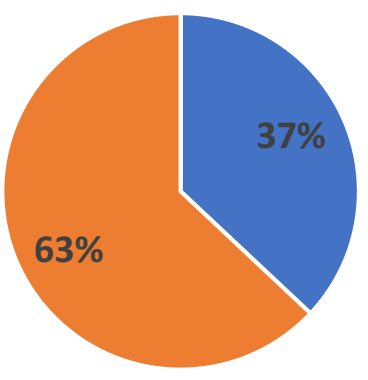

- Remotely proctored

- Not proctored (open-ended)

Fig. 4 Proctoring the assessment

were also considered separately since the assessment nature and evaluation method could have different features. Hence, in this research specific questions were prepared to evaluate the assessment methods of assignment and project-based works separately. For assignment-based assessment, various options of submission and evaluation methods were provided to respondents to prioritize according to their appropriateness to their respective modules.

- Report (conducting investigation and submitting report)

- Open-book assignment (open-book and unproctored problems)

- Professional presentation (audiovisual demonstration of the student's understanding)

- Annotated bibliography (summarize the essential ideas contained in a document)

- Fact sheet (provides information to readers in a clear and concise format about company/topic)

- E-portfolio (compile their best or representative work of the semester)

As shown in Fig. 5, 28 respondents among 50 participants have preferred report submission as their 1 st choice for their module assessment. An open-book assignment is preferred as the second option by 20 respondents and as the 1 st option by 10 respondents. Presentation has been selected by 12 respondents as the 3rd option, and the same number of respondents has selected it as the 4th option. Annotated bibliography was selected as the last option by 14 respondents. E-portfolio is also appeared to be less preferred; twelve respondents put as last option and 11 respondents put as their 5th option. From the respondents' response, fact sheet was also appeared to be less preferred; fourteen and six respondents have put as their 5th and last preference, respectively.

Consequently, the assessment type most preferred by the faculties for their respective modules were found to be conducting investigation and submitting a report online through the college Moodle platform. The total number of respondents who have 


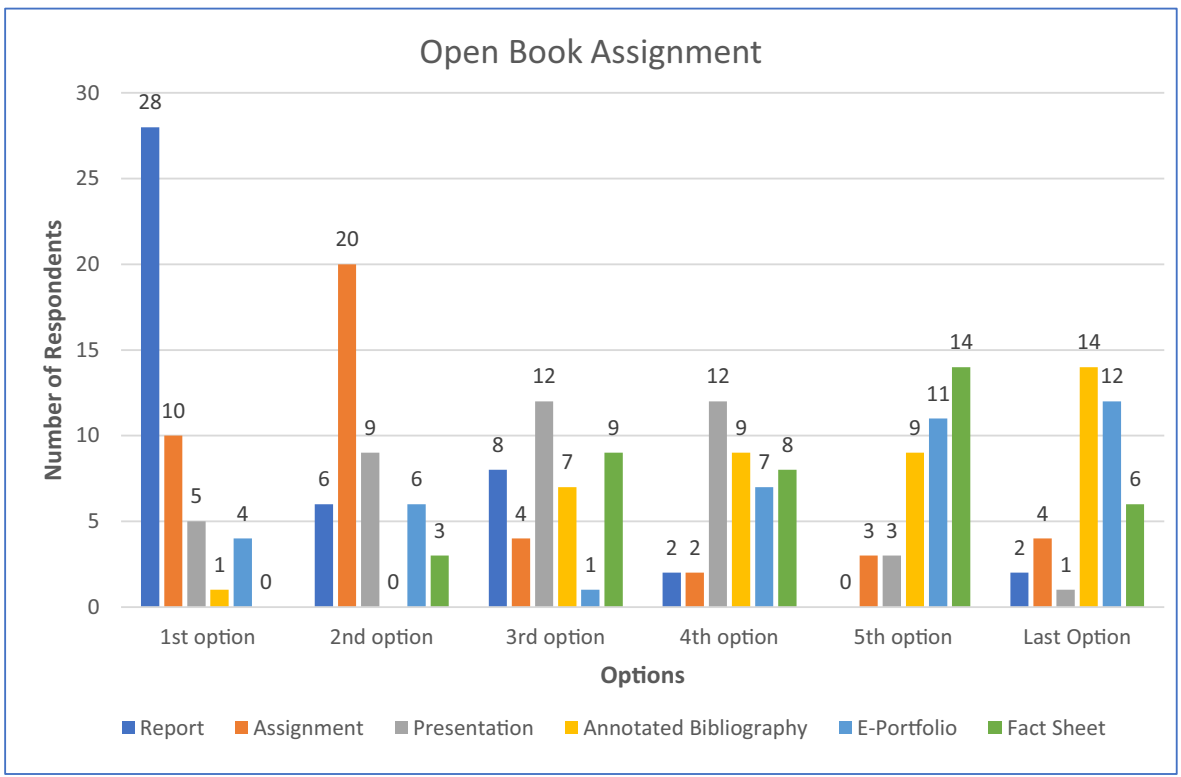

Fig. 5 Open-book assignment

chosen report writing as the 1 st and 2 nd options were 34 (28 as their 1 st option and 6 as their 2 nd option). Also, a total of 30 faculties (20 as their 2 nd option and 10 as their 1 st option) have put open-book assignment as their preference.

In general, the preferences of the faculties for report and open-book assignment were higher compared to the other options. The main reasons could be the assessment nature which enables to cover the learning outcomes of the modules and controlling the academic integrities through the Turnitin submission.

The project-based assessment type is basically a research-based assessment which would require more time and detail analysis. This assessment would also have various forms of submissions and presentations.

Hence, the following four types of submission and evaluation methods were provided to respondents to prioritize based on their preference respective to their module.

- Report evaluation

- Online presentation evaluation

- PPT with voice over evaluation

- Simulation/model/prototype evaluation

As shown in Fig. 6, report evaluation and simulation/model/prototype assessments have got the first preference by 21 and 12 respondents, respectively. As a second option, online presentation and report evaluation got the highest preference with 22 and 12 respondents, respectively. PPT with voice over was the 3 rd and 4 th options for 34 respondents. Fifteen respondents have put simulation/model/prototype assessment as their last option. As the nature of the modules is not the same, the preference of the respondents was also influenced by module type. One reason for significant number of respondents to choose simulation/model/prototype as their first and last option could be 


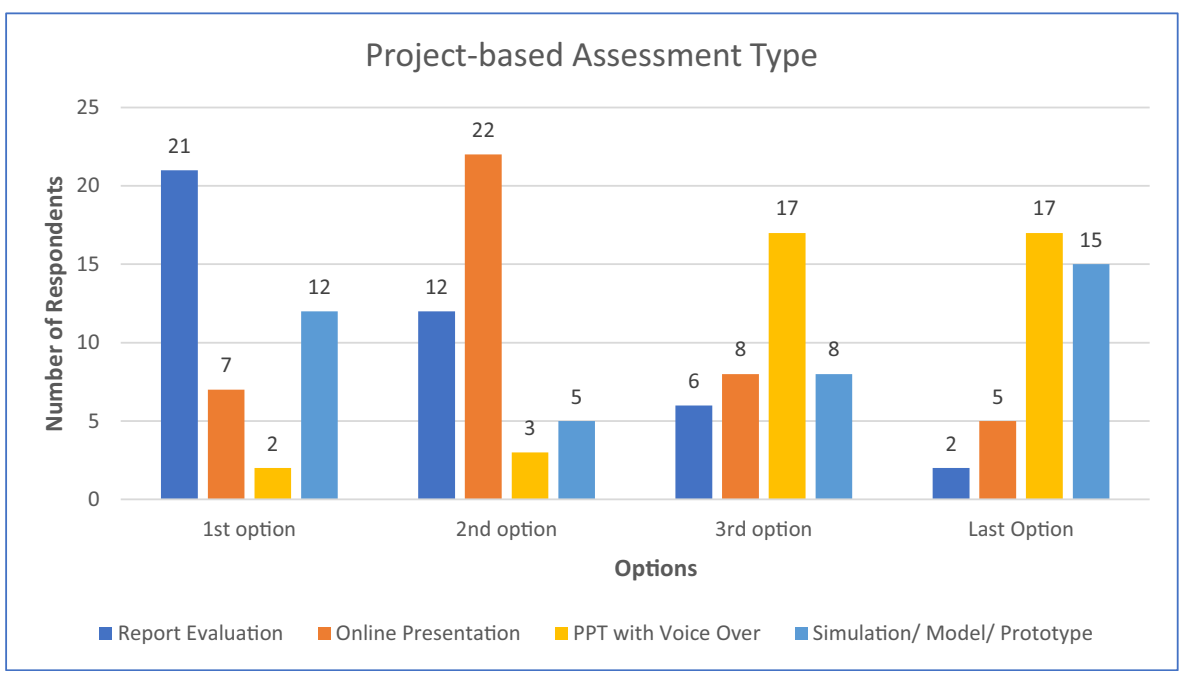

Fig. 6 Project-based assessment

the nature of their respective module. For some modules such as finite element and stress analysis, simulation is the core component of the module, and hence, the assessment should evaluate the simulation performance of the students using ANSYS software. On the other hand, modules such as communication, and entrepreneurship and new venture creation do not require simulation/model/prototype. The other possibility that needs to be considered is the possibility of using combined evaluation methods for project-based assessment. In a project and simulation/model/prototype assessments, the evaluation could incorporate online presentation or PPT with voice over presentation in addition to the submitted materials.

\subsection{Challenges of remote assessment}

Under the remote assessment, four distinct types of challenges were provided to respondents to prioritize based on the degree of the challenge. In addition, an openended question was included to respondents to mention any other challenges which are not listed in the questionnaire. As shown in Fig. 7, respondents have prioritized the challenges from 1 to 4 . Infrastructure problem and academic integrity violation were selected by 20 and 19 respondents as the 1st degree challenge, respectively. The infrastructure problem could be challenging particularly for modules which require computer lab and high internet speed to carry out certain assessments, such as simulation works using ANSYS software. In this regard, the college has made significant effort in providing remote access of the college computer labs to students.

The confidence on students' commitment to submit the assessment through the Moodle plat form was also considered by 24 respondents as the 2 nd degree challenge. To address this concern, the college implemented various student follow-up methods to encourage them to attend online classes and submit assessments. Achievement of the module learning outcome was considered by respondents as another challenge and twenty-six respondents have put as the 4th degree challenge, and only 5 respondents have selected it as the 1 st degree challenge. 


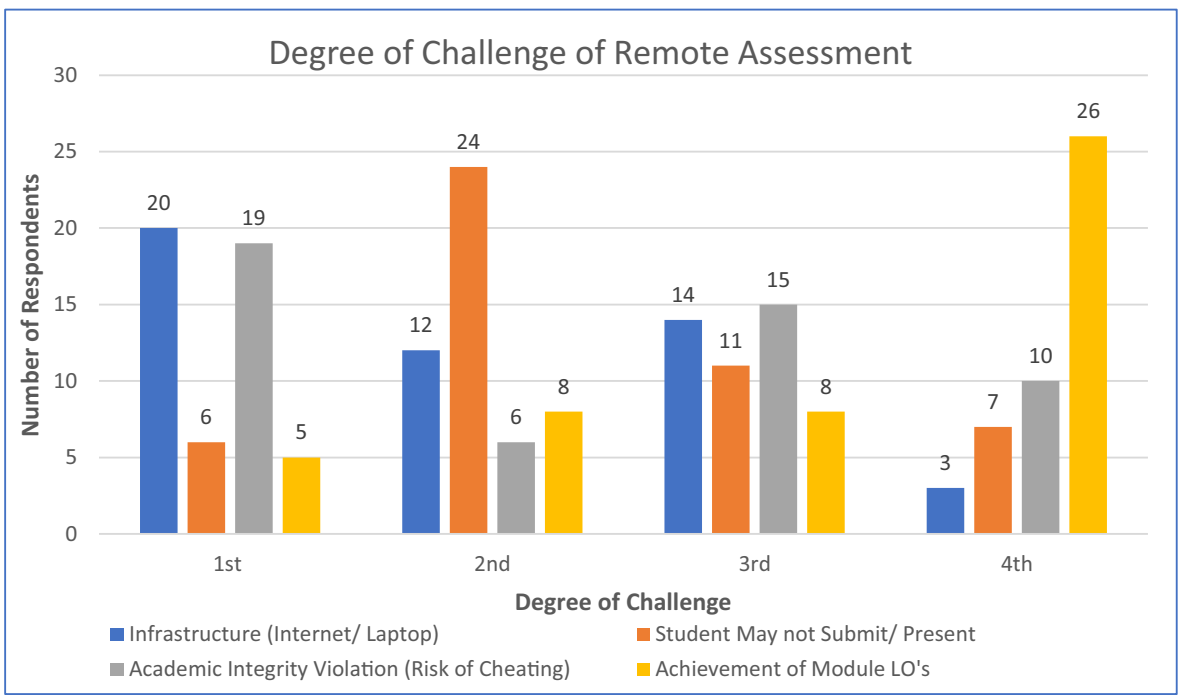

Fig. 7 Degree of challenges of remote assessment

Since violation of academic integrity is one of the major concerns in remote assessment, in the questionnaire, eight types of assessments were provided to respondents to prioritize them in descending order in preventing academic integrity violation starting from 1st to last options. The assessment types presented to respondents were as follows:

- Different question paper for each student

- Online presentation and discussion

- Assignment (open-book and unproctored)

- Report evaluation

- Professional presentations

- Annotated bibliography

- Fact sheet

- E-portfolio

As shown in Fig. 8, preparing different questions to each student were found to be the first and second option for 16 and 7 respondents, respectively, to minimize academic integrity violation. Online presentation was also appeared to be good option by many respondents to control academic integrity violations. Eighteen respondents put online presentation and discussion as their second option and 11 respondents as their 1 st option. Professional presentation was also identified as one of the assessment methods that enable to control academic integrity violations. Thirteen and 8 respondents have put professional presentation as the 3rd and 2nd option, respectively. E-portfolio has appeared as the 7 th and last option to 12 and 10 respondents, respectively, to prevent academic dishonesty. 


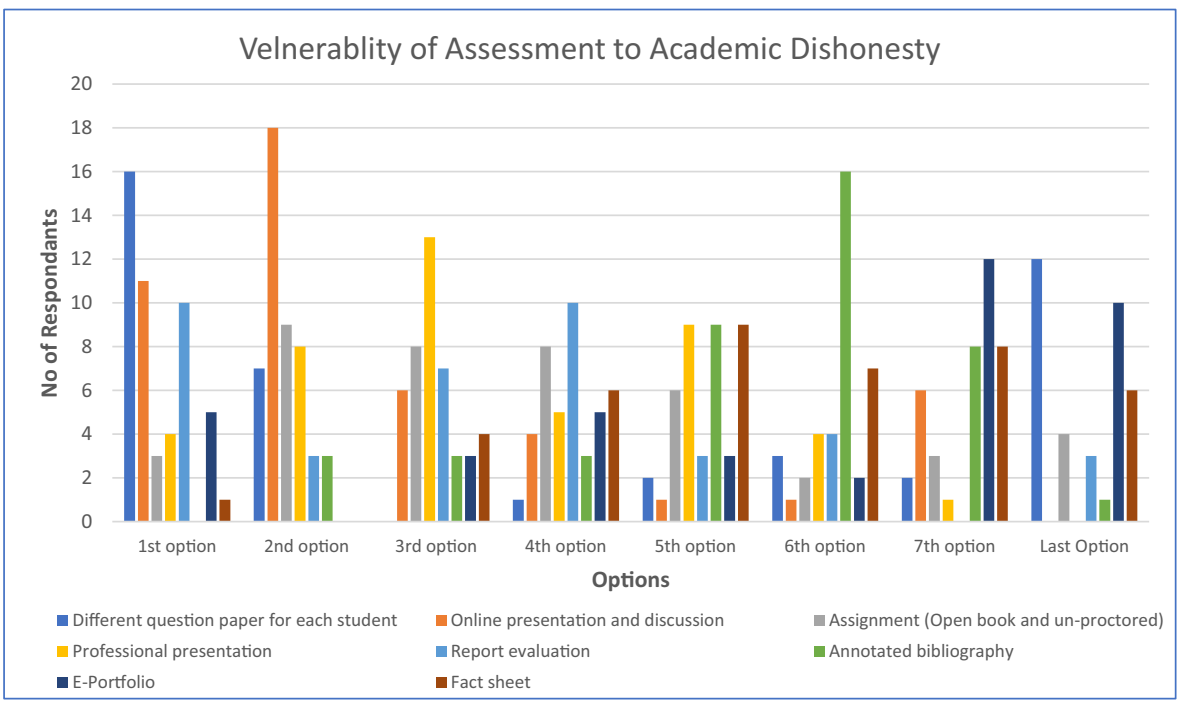

Fig. 8 Vulnerability of assessments to academic dishonesty

\section{Conclusions and recommendations}

The current study was conducted to assess the challenges of remote assessment in higher education institutions in COVID-19 lockdown period taking Middle East College (MEC) as a case study. In the study, the types of remote assessments, the precautions to be taken during remote assessment preparation, and the quality criteria for the remote assessments were reviewed. To investigate the remote assessment challenges faced by the faculties of different programs in MEC, a questionnaire was prepared and distributed to all faculties through Google Forms and 50 responses were collected.

As proctoring students remotely requires appropriate infrastructure, most respondents have preferred unproctored assignment/project-based assessment with higher level of challenge than proctored question-based assessment which can be completed relatively in a shorter time, maximum $3 \mathrm{~h}$. Depending on the module nature, unproctored assignment/project-bases assessments would have different submission types and evaluation methods. The options provided to respondents for submission and evaluation types were project report, open-book assignment, professional presentation, annotated bibliography, factsheet, and E-portfolio. Among the options project report submission and unproctored open-book assignment were the most preferred assessments by the respondents. Twenty-eight respondents were put report submission as their first option and twenty respondents put unproctored open-book assignment as their second option.

For the questionnaire provided to evaluate the degree of challenges during COVID19 lockdown time, most faculties have put infrastructure problem and academic dishonesty as the first challenge. Students' commitment to submit assessments was also appeared as a concern by 24 faculties, and put as the second challenge. To address this challenge, the college has devised various follow-up methods in faculty and department head level to encourage students to attend online classes and submit the 
assessments. The challenges related to infrastructure and commitment of students to attend online classes and submit assessments could be solved by the college in collaboration with the students and other stockholders the future since both current challenges were created unprecedently due to COVID-19. However, academic dishonesty problem is not a tentative and COVID-19-related problem and needs further investigation. Hence, the assessment type used for unproctored assessment was taken as one prevention method and respondents were asked to identify the appropriate assessment method. As a result, 16 and 7 respondents were put preparing different question for each student as their first choice and second choice to prevent academic dishonesty. This approach could be practical if the number of students in one class room is relatively small in number and the faculties are able to manage it in preparation of the question and assess the answer scripts within the time frame of the semester. The other option appeared to be good for prevention of academic dishonesty was online presentation. Eighteen respondents preferred online presentation as their second option and 11 respondents as their first option. Using combined evaluation methods for an assessment could be more appropriate to address the learning outcomes of the module and at the same time minimize the risk of academic dishonesty. The effect of academic dishonesty is not only limited within the unfair distribution of marks to students but also it adversely affects the teaching-learning process. Students who are striving to acquire knowledge and expect the reward accordingly to their effort will be demotivated and the quality of learning will drop. In addition to various controlling methods used during assessment time, higher education institutions have to create awareness among students on academic integrity issues and develop the ethics of students through the learning process by incorporating in the curricular and cocurricular plans.

Acknowledgments The authors acknowledge Middle East College and the faculties of the college for providing the necessary information in the case study of the current research work.

\section{Compliance with ethical standards}

Hereby the authors consciously assure that for the manuscript "Challenges of remote assessment in higher education in the context of COVID-19: a case study of Middle East College" the following is fulfilled:

1. This material is the authors' own original work, which has not been previously published elsewhere.

2. The paper is not currently being considered for publication elsewhere.

3. The paper reflects the authors' own research and analysis in a truthful and complete manner.

4. The paper properly credits the meaningful contributions of co-authors and co-researchers.

5. The results are appropriately placed in the context of prior and existing research.

6. All sources used are properly disclosed (correct citation).

7. All authors have been personally and actively involved in substantial work leading to the paper and will take public responsibility for its content.

\section{References}

Al-Shammari, Z. (2011). Assessment of student learning outcomes: Indicators of strengths and weaknesses. In ICERI2011 Proceedings (pp. 4228-4230).

Archer, E. (2017). The assessment purpose triangle: Balancing the purposes of educational assessment. Paper presented at the Frontiers in Education. 
Capsim. (2020). The five levels of assessment in higher education. Retrieved from https://www.capsim.com/ blog/the-five-levels-of-assessment-in-higher-education/

Cooper, V., \& Tschobotko, A. (2020). COVID-19 - higher education and student related challenges. Bevan Brittan LLP.

Haynie III, W. J. (2003). Effects of take-home tests and study questions on retention learning in technology education. Volume 14 Issue 2 (spring 2003).

Hsiao, Y. P., \& Watering, G. A.v. d.. (2020). Guide for choosing a suitable method for remote assessment considerations and options: University of Twente.

Kearns, L. R. (2012). Student assessment in online learning: Challenges and effective practices. Journal of Online Learning and Teaching, 8(3), 198.

Kebritchi, M., Lipschuetz, A., \& Santiague, L. (2017). Issues and challenges for teaching successful online courses in higher education: A literature review. Journal of Educational Technology Systems, 46(1), 4-29.

McCabe, D., Butterfield, K., \& Trevino, L. (2012). Cheating in college: Why students do it and what 633 educators can do about it. Baltimore: Johns Hopkins Press.

MEC. (2020a). Alternative/revised assessment preparation guide for spring and summer 2020. Middle East College.

MEC. (2020b). Supportive measures and assessment approach for spring and summer 2020. Middle East College.

Nair, V. (2020). Classes suspended at schools and all institutions for a month. Oman daily Observer. Retrieved from https://www.omanobserver.om/classes-suspended-at-schools-and-all-institutions-for-a-month/

Observer, O. (2020). Muscat lockdown from Friday, schools suspended until further notice. In Oman Observer Retrieved from https://www.omanobserver.om/muscat-supreme-commitee/.

Organizing your social sciences research paper. (2020). Retrieved from https://libguides.usc.edu/writingguide/ annotatedbibliography

Rutgers. (2020). Remote exams and assessments. Retrieved from https://sasoue.rutgers.edu/teaching-learning/ remote-exams-assessment\#special-advice-for-open-book-assessment-in-quantitative-courses

WHO. (2020). Modes of transmission of virus causing COVID-19: implications for IPC precaution recommendations. Retrieved from https://www.who.int/news-room/commentaries/detail/modes-oftransmission-of-virus-causing-covid-19-implications-for-ipc-precaution-recommendations

Zhang, W., Wang, Y., Yang, L., \& Wang, C. (2020). Suspending classes without stopping learning: China's education emergency management policy in the COVID-19 outbreak: Multidisciplinary digital publishing institute.

Publisher's note Springer Nature remains neutral with regard to jurisdictional claims in published maps and institutional affiliations.

\section{Affiliations}

\section{Fiseha M. Guangul ${ }^{1}$ - Adeel H. Suhail ${ }^{1}$ - Muhammad I. Khalit ${ }^{1} \cdot$ Basim A. Khidhir $^{1}$}

Adeel H. Suhail

adeel@mec.edu.om

Muhammad I. Khalit

milham@mec.edu.om

Basim A. Khidhir

basim@mec.edu.om

1 Department of Mechanical Engineering, Middle East College, PB 79, PC 124, Al Rusayl, Muscat, Oman 